RAD Conference Proceedings, vol. 4, pp. 50-54, 2020

ISSN 2466-4626 (online) | DOI: 10.21175/RadProc.2020.10

www.rad-proceedings.org

\title{
LOCALIZATION AND SHAPE OF STENOSES IN PERIPHERAL LUNG CARCINOMA DIAGNOSED BY METHODS OF VB AND FB
}

\author{
Mitko Mitev ${ }^{*}$, Evelin Obretenov² \\ ${ }^{1}$ Department of Medical Physics, Biophysics, Roentgenology and Radiology, Faculty of Medicine, Department of \\ Diagnostic Imaging, University Hospital 'St. Kirkovich', Trakia University - Stara Zagora, Stara Zagora, Bulgaria \\ ${ }^{2}$ Department of Special Surgery/Thoracic Surgery, Vascular Surgery, Pediatric Surgery and Orthopedics and \\ Traumatology, Faculty of Medicine, Clinic of Thoracic Surgery, University Hospital 'St. Kirkovich', Trakia \\ University - Stara Zagora, Stara Zagora, Bulgaria
}

\begin{abstract}
Introduction. The study aim to present the diagnostic capabilities of virtual bronchoscopy (VB) and fiberoptic bronchoscopy $(F B)$ for determining the localization and shape of stenoses in patients with peripheral lung carcinoma. Materials and methods. A systemic study was performed on 9o patients, 61 patients of them (67.78\%) are men and 29 (32.23\%) are women, 44-85 years of age, with endobronchial disease, using the FB and VB methods, over the period 2013-2020. Results. As a result of the study of 220 patients aged 11-83 years (54.36 \pm 17.24$)$, in 90 patients after VB (40.91\%; 61 men - 67.78\% and 29 women - 32.23\%) and in 86 patients after FB (39.09\%; 61 men - 70.93\% and 25 women - 29.07\%) peripheral lung carcinoma was found. Cases of men diagnosed with VB and FB with peripheral left carcinoma predominate (65.38\% and $71.43 \%$, respectively) compared to those in women (34.62\% and $28.57 \%$, respectively) and as well as with regard to cases with peripheral right carcinoma. Significant differences in the size of the stenoses were found in both sexes with peripheral carcinoma $(U=4.112, P=0.0000)$. Conclusion. $V B$ allows high-quality visualization of stenoses and poststenotic areas that cannot be achieved with $F B$ in peripherally located processes. Through VB peripheral branches of 5-6 order can be reached. VB makes it possible to examine the areas located after the tumour formation.
\end{abstract}

Key words: $F B$, localization, peripheral lung carcinoma, shape of stenoses, VB

\section{INTRODUCTION}

Virtual bronchoscopy (VB) is a new CT-based imaging technique that allows three-dimensional imaging (3D) and airway assessment. VB is a noninvasive modality focused on the ability to detect central and more peripheral airway abnormalities. Preliminary studies have shown the applicability and usefulness of VB in patients with primary or metastatic carcinomas of the lung and mediastinum [1]-[4].

The combination of information from virtual bronchoscopic images and CT images allows assessing not only the intraluminal spread of the tumour, but also the extraluminal expansion of the mass and its connection with the bronchial tree. VB allows the bronchial tree to be assessed distally and to stenoses that cannot be passed with FB (fiberoptic bronchoscopy) [5]-[10], [3], [2], [4].

Peripheral carcinoma originates in the distal part of the subsegmental bronchi. It appears late. The leading symptom of this disease is chest pain [1], [3].

The difficult diagnostics, the severity of the disease associated with danger to life, as well as the often poor health of patients require the use of modern noninvasive methods for imaging and the implementation of studies for their diagnostic capabilities.
The study aims to present the diagnostic capabilities of virtual bronchoscopy (VB) and fiberoptic bronchoscopy (FB) for determining the localization and shape of stenoses in patients with peripheral lung carcinoma.

\section{MATERIALS AND METHODS}

Diagnostic studies were performed on 220 patients with endobronchial disease by the methods of FB and VB over the period 2013-2020. Of these, 90 patients with VB and 86 patients with FB were diagnosed with peripheral lung carcinoma. Patients with peripheral cancer, aged $44-85$ years, were the subject of this study. 61 patients of them $(67.78 \%)$ are men, and $29(32.23 \%)$ are women.

Patients were divided into four age groups. Twenty two patients had negative results for carcinomas and were diagnosed with other diseases (Table 1).

Philips Essenca (Philips Medical Systems, Cleveland, Ohio, USA) was used for VB, whereas FB was performed on Olympus BF PE2 (Olympus Corp., Tokyo, Japan) and Fujinon EP-120 T (Fujinon-Fujifilm Corp., Saitama, Japan). The VB study was conducted using MDCT Philips Essenca and 64 MDCT Siemens Definition AS (Siemens Aktiengesellschaft, Munich, Germany). 
Table 1. Diagnosed patients

\begin{tabular}{|l|l|l|l|l|}
\hline Diagnosis & \multicolumn{2}{|l|}{$\begin{array}{l}\text { Peripheral } \\
\text { carcinoma } \\
\text { Number (n) }\end{array}$} & \multicolumn{2}{l|}{ Other } \\
& Number (n) \\
\hline Age group & Male, & Female, & Male, & Female, \\
(yrs)/Sex & $\mathrm{N}$ & $\mathrm{n}$ & $\mathrm{n}$ & $\mathrm{n}$ \\
\hline $1(26-35)$ & - & - & - & 1 \\
$2(36-55)$ & 8 & 6 & 4 & 2 \\
$3(56-75)$ & 46 & 19 & 5 & 4 \\
$4(>75)$ & 7 & 4 & 3 & 3 \\
\hline Total & 61 & 29 & 12 & 10 \\
\cline { 2 - 5 } & 90 & 22 \\
\hline
\end{tabular}

\section{RESULTS}

Out of the 220 patients with lung carcinomas studied in total, as a result of the VB, peripheral carcinoma was found in 90 patients (40.91\%): 29 (13.18\%) women and 61 (32.27\%) men aged 44-85 years $(54.36 \pm 17.24)$. In the diagnosis by FB method, out of the 220 patients studied in total, peripheral lung carcinoma was registered in 86 patients (39.09\%): 25 (11.36\%) women and 61 (32.27\%) men (Figure 1).

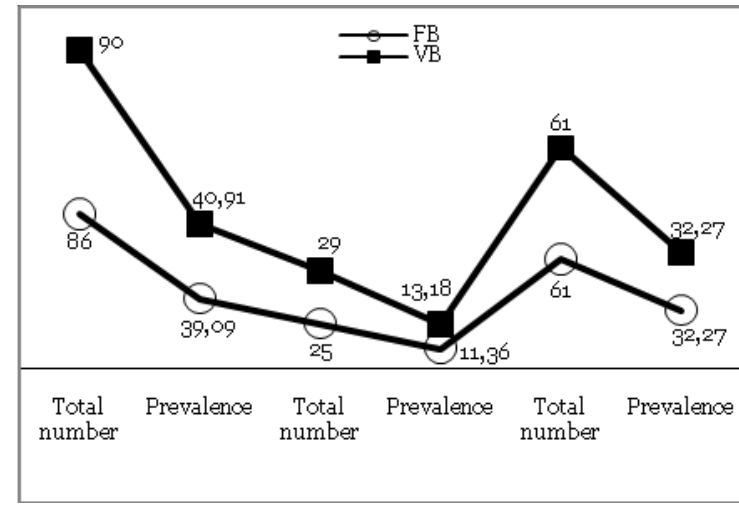

Figure 1. Number and percentage distribution of cases of peripheral lung carcinoma, found in men and women studied by the methods of $\mathrm{FB}$ and $\mathrm{VB}$

No significant differences (H-test, $\mathrm{p}>0.05$ ) were found between the number of patients with peripheral carcinoma diagnosed by the two methods, as well as their percentage distribution between men and women.

\subsection{Localization}

Out of the 90 patients with peripheral lung carcinoma studied by the VB method, 37 patients (44.12\%) were diagnosed with right localization. 26 of them were men (28.89\%) and 11 (12.23\%) were women. The remaining $53(58.89 \%)$ patients had lung carcinomas with peripheral left localization (35 men, $38.89 \% ; 18$ women, $20.0 \%)$. The number of men with peripheral right carcinoma was 2.36 times bigger than that of women, and with peripheral left carcinoma 1.94 times bigger than that of women. In both men and women, peripheral lung carcinomas with left localization predominated.

Out of the FB diagnosed 86 patients in total with peripheral lung carcinoma, 36 patients $(41.86 \%)$ had peripheral right localization (25 men, 29.07\%; 11 women, $12.79 \%)$, and the remaining 50 patients 51
(58.14\%) had peripheral left localization (36 men, 41.86\%; 14 women, 16.28\%; Figure 2).

The number of men with peripheral right carcinoma was 2.27 times bigger than women, and men with peripheral left carcinoma were 2.57 times more than women with the same localization, found by the method of FB. The difference between men and women with peripheral left carcinoma was higher in the results of FB, while this difference was higher in the results of VB between men and women with peripheral right carcinoma. Nevertheless, in both diagnostic methods, both sexes are dominated by peripheral lung carcinomas with left localization compared to those with right localization (Figure 2).

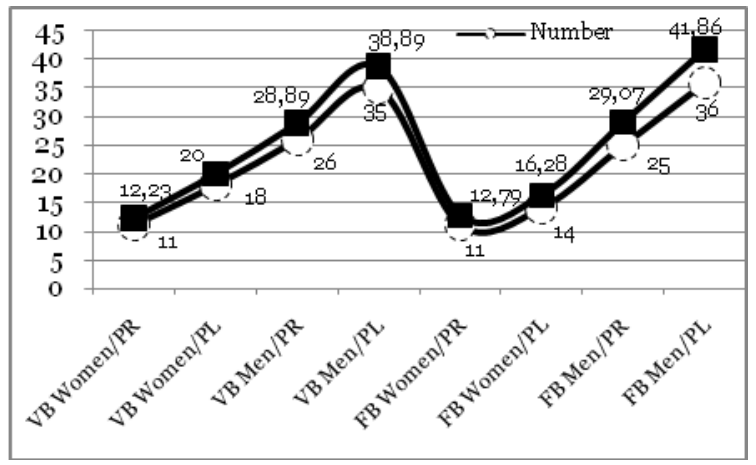

Figure 2. Localization of peripheral carcinoma in both sexes studied by VB and FB

In men with peripheral right VB localization, most patients (20) were aged 55-62 years (third age group), followed by those aged 45-54 years ( 6 patients; second group). No peripheral carcinomas were found in men from the first and fourth groups.

The age range of patients diagnosed with peripheral right carcinoma by FB was 45-62 years and one patient less was reported than by VB (25 and 26 , respectively by FB and VB).

In men with peripheral left localization 35 patients aged 44-84 years were diagnosed by VB. The greatest is the number of patients from the third age group (26), followed by those from the fourth age group (7 patients) and the second age group (2 patients).

In $\mathrm{FB}$, peripheral right carcinoma was diagnosed in one patient more than in VB (36 and 35, respectively). This was most likely due to a displacement of the changes from peripheral to central as a result of mucosal oedema.

In women with peripheral right localized carcinoma, 11 patients aged 40-77 years were diagnosed by VB. The largest was the number (7 patients) of the patients from the third age group, followed by the second group (3 patients) and the fourth group (one patient).

In $\mathrm{FB}$, the results for women with peripheral right localized carcinoma coincide with those of $\mathrm{VB}$ (11 patients in VB; 11 patients in $\mathrm{FB}$ ).

Eighteen women aged 40-75 years were diagnosed with peripheral left localization by VB, with the largest number of patients in the third age group (12 patients aged $57-75$ years), followed by that in the second age 
group (45- 54 years) and the fourth age group (from 76-81 years) with an equal number of patients (3 each).

In $\mathrm{FB}, 14$ women with peripheral left localized carcinoma were found, i.e. 4 less than those diagnosed in VB (18 and 14 patients, respectively in VB and FB).

Patients aged 55-62 years showed the highest number of diagnosed persons with peripheral carcinoma in both sexes by both methods.

No peripheral carcinomas were found in the studied patients of the first age group in both sexes by both methods.

The differences in the percentage distribution of peripheral carcinomas by localization, both in men and women, compared for the two methods were not statistically significant (U-test, $\mathrm{p}>0.05$ ).

\subsection{Shape}

CT characteristics of the lesions show that, as in central carcinomas, peripheral malignant lesions have different characteristics of the processes of exobronchial and endobronchial growth. The exobronchial ones cause pronounced arcuate eccentric compression, leading to irregular eccentric stenosis. Those with endobronchial growth, due to the small size of the peripheral bronchi, give rapid high-grade stenoses and obliterations. In exobronchial and endobronchial processes, larger formations result in more bronchi affected. At the most peripherally located changes, small lesions, due to remoteness, cannot be examined. On CT, depending on the type of tumour and the size of the bronchi, they are seen as oval lesions with spiculous changes, some of which are associated with changes in the main bronchi and carina from lymphogenic disseminations, and some give changes in parenchymal aeration as a result of high-grade stenoses and obliterations. In men and women with peripheral right and peripheral left localization, circular stenotic changes and less irregular stenotic changes predominate in $\mathrm{VB}$. In $\mathrm{FB}$, the shape of the changes in peripheral carcinomas is defined as concentric or eccentric stenosis, mucosal hyperemia, and complete obstruction (Figure 3-5).

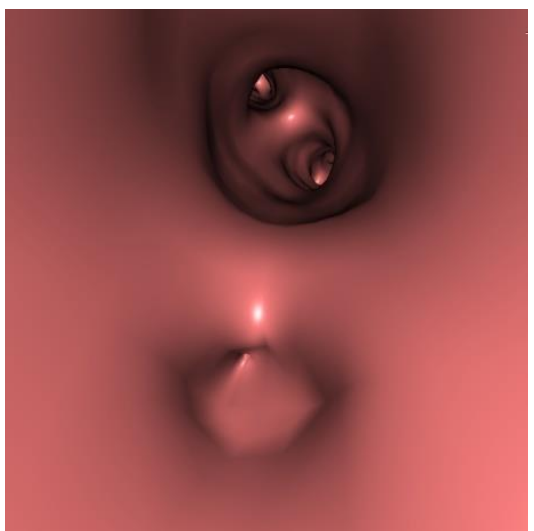

Figure 3. Peripheral carcinoma, VB (Original, Mitev)

Significant differences in the size of the stenoses were found in both sexes with peripheral carcinoma $(\mathrm{U}=4.112, \mathrm{P}=0.0000)$

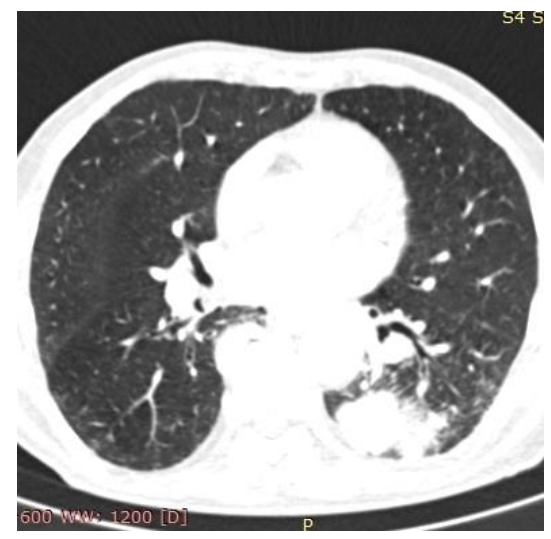

Figure 4. Peripheral carcinoma, CT (Original, Miitev)

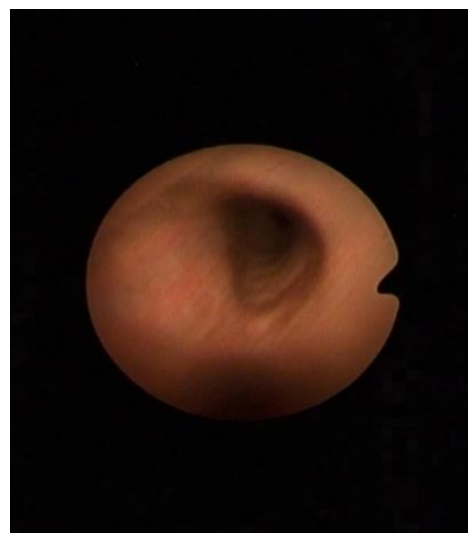

Figure 5. Peripheral carcinoma, FB (Original, Obretenov)

\section{DisCUSSION}

The study shows that tracheobronchial stenoses in peripheral lung carcinomas are well recognized with VB and moreover, the virtual method allows highquality visualization of stenoses and poststenotic areas that cannot be achieved with FB in peripheral processes.

A comparison of patients treated on 6 slices CT with 64 slices MDCT shows a significant difference in the quality, sharpness and morphological imaging of the tracheobronchial tree in peripheral lesions and depending on the sex, age and height of the patient leads to peripheral branches of $5^{\text {th }}-6^{\text {th }}$ generation. Reaching more peripheral areas is due to improvements in computer hardware and software.

In peripheral carcinomas, in contrast to the central ones, a higher number of false positive and false negative results are observed due to the small size of the lumen and observance of changes in secretions, mucosal changes or other nosological diseases associated with changes in the correct topic, shape and bronchial dimensions.

In some patients, due to more pronounced mucosal oedema, the changes were registered in more anterior positions and were reported as central. In changes with incomplete obstructions and combination with multiplanar reconstructions, VB allows examination of the areas distal to the stenoses. 
Regarding the form of the changes, more and higher degree of stenoses and obturations were found in comparison with FB. The diagnosed higher degrees of stenosis are an indirect sign of changes in the bronchial mucosa. In FB, changes in the mucosa, secretions and a larger number of changed stenotic areas are particularly found.

In peripheral neoplastic processes involving the bronchi to the third to fourth generation of the bronchial branches, in VB it is seen that although with small lesions, the number of patients with complete bronchial obstruction is big due to external compression or endoluminal defect. In $5-7 \%$ of the cases, incomplete obstruction is found as a result of germination and infiltration of the bronchi. VB makes it possible to examine the areas located after the tumour formation. In some patients, in the adjacent bronchi of tumour processes, as a result of external compression, pressing and stenosis of the lumen is found. Peripherally located subsegmental bronchi may not show changes or may show bronchi with complete obstruction. As a result of the small size of the lumen, complete compression and obliteration of the bronchi is achieved. In distally located lesions, the results are identical to those of the real FB. In more distal bronchi ( $4^{\text {th }}-5^{\text {th }}$ generation), in VB, depending on age, sex and the presence of chronic lung disease, sometimes more peripheral areas are reached. In peripheral carcinomas, a higher degree of stenoses and a higher number of obliterations are observed.

The possibility to determine the size of the changes and the shape of the finding by the VB method leads to indirect conclusions about the presence or absence of malignant or benign findings or for compression by one or more lymph nodes. According to Li et al., the shape of the findings is important, i.e. those with a regular round shape and sharp outlines indicate a presumed benign process [13]. The oval findings with a smooth shape indicate, according to the authors, a malignant process or significantly enlarged lymph nodes. Those with uneven irregular outlines, multiple polycyclic changes, protruding unevenly to the lumen, are characteristic of malignant aggressive processes leading to infiltration of adjacent structures. Thus, indirectly, the changes support staging and behavioral choice of treatment, intervention, or surgery. Greater spatial clarity is always achieved in combination with axial and multiplanar images.

The magnitude of the measured changes can also be considered to be important in determining the invasiveness of the process. Depending on the size (length) of the altered areas in the trachea and main bronchi, VB may indirectly indicate the stage of the carcinoma. Thus, according to Asano et al., $20 \mathrm{~mm}$ lesions in the area of the trachea and main bronchi indicate directly the $\mathrm{T}_{3}$ stage of the neoplasms [10].

Advantage of the presented research study performed with 64 slices MDCT and comparing the results of $\mathrm{VB}$ with those of $\mathrm{FB}$ is that an increase in the percentage of accuracy in determining the location of neoplasms, their size, degree of stenosis, as well as prestenotic and poststenotic processes is achieved.

In peripheral carcinomas, the changes observed in VB were $80.35 \%$ compared to $89.10 \%$ recorded in $\mathrm{FB}$.
In peripheral carcinomas, the sensitivity in $\mathrm{VB}$ is $80.36 \%$ compared to $85.53 \%$ in FB. Better performance is found in favour of $\mathrm{FB}$ as a "gold standard".

Schlathölter et al., Wever et al. achieved high success rates in peripheral carcinomas and, as in this study, reached $7^{\text {th }}$ generation of lung branches [14], [15]. According to a number of recent studies, the frequency of peripheral lung lesions has increased with the introduction of lung carcinoma screening through the use of low-dose CT. The authors emphasize the importance of choosing the right way to find the changes, to correctly determine the location, as close as possible to the carcinoma, the exact sampling by the bronchoscopist, etc. [10], [16]-[20]. The development of technologies, devices and software shows that the methodology is relevant at the present stage and allows reaching the bronchi of $9^{\text {th }}-10^{\text {th }}$ generation, but with significantly higher exposure of patients [21] than in this study with low-dose protocols and reaching the bronchi of $6^{\text {th }}-7^{\text {th }}$ generation. The VB method is applicable to differentiate benign from malignant neoplastic processes, as well as to perform staging.

\section{CONCLUSION}

VB allows high-quality visualization of stenoses and poststenotic areas that cannot be achieved with FB in peripherally located processes. Through VB peripheral branches of $6^{\text {th }}-7^{\text {th }}$ generation can be reached. VB makes it possible to examine the areas located after the tumour formation.

Acknowledgements: The authors would like to thank the Trakia University - Stara Zagora, the Republic of Bulgaria, for the funding received under the National Research Program "Young Scientists and PhD Students" and the support provided.

\section{REFERENCES}

1. М. А. Митев, Виртуална бронхоскопия с мултидетекторен компютърен томограф, Дисертация ОНС Доктор, Тракийски университет Стара Загора, Катедра Мед. физика, биоф., рентг., рад., Стара Загора, Бг, 2017 (M. A. Mitev, "Virtual bronchoscopy with Multidetector computed tomography," Ph.D. dissertation, Trakia UniversityStara Zagora, Dept. of Med. Physics, Biophysics, Roentg, Rad., Stara Zagora, BG, 2017).

2. P.M. Kotlyarov, "Virtual bronchoscopy for tumors and Traumatic Lesions of the Aitways," Open access peerreviewed chapter, in Intervent. Pulm. Pulm. Hypert. Upd. Sp. Top., UK: IntechOpen, 2020, ch. 4 pp. 189-254 https://doi.org/10.5772/intechopen.78454

3. M. Mitev, N. Trajkova, D. Arabadzhiev, S. Valkanov, N. Georgieva, E. Obretenov, "Virtual bronchoscopy importance of the method application and prospects for tumors of the trachea and bronchi," Trakia J. Sci., vol. 15 , no. 3 , pp. $269-273,2017$. https://doi.org/10.15547/tjs.2017.03.018

4. M. Mitev, E. Obretenov, D. Valchev, "Localization and shape of stenoses in central lung carcinoma sensitivity and precision of MDCT VB and FB," Acta 
Clin. Croat., vol. 59, no. 2, pp. 252-259, Sep. 2020 https://doi.org/10.20471/acc.2020.59.02.08

5. T. Fleiter, E.M. Merkle, A.J. Aschoff, G. Lang, M. Stein, J. Görich, F. Liewald, N. Rilinger, R. Sokiranski, „Comparison of Real-Time Virtual and Fiberoptic Bronchoscopy in Patients with Bronchial Carcinoma: Opportunities and Limitations," A. J. R., vol. 169, no. 6, pp. 1591-1595, Dec. 1997

https://www.ajronline.org/doi/pdfplus/10.2214/ajr.16 9.6.9393172

PMid: 9393172

6. F. Liewald, G. Lang, T.H. Fleiter, R. Sokiranski, G. Halter, K.H. Orend, "Comparison of virtual and fiberoptic bronchoscopy," Thor. Cardio-vasc. Sur., vol. 46, no. 6, pp. 361-364, 1998.

https://doi.org/10.1055/s-2007-1010254

PMid: 9928859

7. H.P. McAdams, Ph.C. Goodman, P. Kussin, "Virtual Bronchoscopy for Directing Transbronchial Needle Aspiration of Hilar and Mediastinal Lymph Nodes: A Pilot Study," A. J. R., vol. 170, no. 5, pp. 1361-1364, May 1998.

https://www.ajronline.org/doi/pdfplus/10.2214/ajr.17 0.5 .9574616 PMid: 9574616

8. A.J. Burke, D.J. Vining, W.F.Jr. McGuirt, G. Postma, J.D. Browne, "Evaluation of airway obstruction using virtual endoscopy," Laryngoscope, no. 110, pp. 23-29, Jan. 2000.

https://onlinelibrary.wiley.com/doi/pdf/10.1097/0000 5537-200001000-00005

PMid: 10646710

9. П. М. Котляров, С. З. Темирханов, К. Е. Флеров, В. А. Гомболевский, Н. В. Черниченко, Н. В. Нуднов, В. А. Солобкий, Виртуальная бронхоскопия в диагностике рака легкого и его распространенности, мониторинге послеоперационных изменений, Вестника РНЦРР МЗ РФ N13, 2013 (Р. M. Kotlayrov, S. Z. Temirhanov, K. E. Flerov, V. A. Gombolevskii, N. V. Chernychenko, N. V. Nudnov, V. A. Solodkiy, "Virtual bronchoscopy in the diagnosis of lung cancer, in the assessment of its spread and in monitoring of post-operative changes," Newspaper RSCX-RR MH RF N13, 2013.)

Retrieved from:

http://vestnik.rncrr.ru/vestnik/v13/papers/flerov v13. $\underline{\mathrm{htm}}$

10. F. Asano, R. Eberhardt, F. Herth, "Virtual Bronchoscopic Navigation for peripheral Pulmonary Lesions," Respiration, no. 88, pp. 430-440, Oct. 2014. https://doi.org/10.1159/000367900 PMid: 25402610

11. N. McAleece, J. D. G., Lambshead, G. L. J. Peterson, "BioDiversity professional statistics analysis software," UK (London): Natural History Museum and Scottish Association for Marine Science, 1997.

Retrieved from:

http://www.sams.ac.uk/peter-lamont/biodiversity-pro Retrieved on: Feb. 1, 2016

12. StatSoft Inc., 2011. Statistica (data analysis software system), version 10. www.statsoft.com. Retrieved from: https://statistica.software.informer.com/10.0/ Retrieved on: Jan. 20, 2011

13. F. Li, Sh. Sone, H. Abe, H. MacMahon, K. Doi,
"Malignant versus Benign Nodules at CT Screening for Lung Cancer: Comparison of Thun-Section CT Findings," Radiology, vol. 233, no. 3, pp. 793-798, Dec. 2004.

https://doi.org/10.1148/radiol.2333031018 PMid: 15498895

14. T. Schlathölter, C. Lorenz, I. Carlsena, S. Renischa, T. Deschamps, "Simultaneous Segmentation and Tree Reconstruction of the Airways for Virtual Bronchoscopy," Proceedings of SPIE, vol. 4684, no. 02, pp. 103-113, 2002.

Retrieved from:

http://citeseerx.ist.psu.edu/viewdoc/download?doi=10. 1.1.19.9064\&rep=rep1\&type $=$ pdf Retrieved on: May 9, 2002

15. W. De Wever, J. Bogaert, J. A. Verschakelen, "Virtual Bronchoscopy: Accuracy and Usefulness - An Overview," Semin Ultrasound CT MRI, vol. 26, no. 5, pp. 364-373, Oct. 2005.

https://doi.org/10.1053/j.sult.2005.07.005 PMid: 16274005

16. St. Leong, T. Shaipanich, St. Lam, K. Yasufuku, "Diagnostic bronchoscopy - current and future perspectives," $J$ Thorac Dis, vol. 5, suppl. 5, pp. S498-S510, Sep. 2013. https://doi.org/10.3978/j.issn.2072-1439.2013.09.08 PMid: 24163743

17. M. Luo, C. Duan, L. Qiu, W. Li, D. Zhu, W. Cai, "Diagnostic Value of Multidetector CT and Its Multiplanar Reformation, Volume Rendering and Virtual Bronchoscopy Postprocessing Techniques for Primary Trachea and Main Bronchus Tumors," PLoS One, vol. 10, no. 9, pp. e0137329, Sep. 2015.

https://doi.org/10.1371/journal.pone.0137329 PMid: 26332466

18. T. Ishiwata, A. Gregor, T. Inage, K. Yasufuku, "Advances in interventional diagnostic bronchoscopy for peripheral pulmonary lesions," Expert Review of Respiratory Medicine, vol. 13, no. 9, Jul. 2019. https://doi.org/10.1080/17476348.2019.1645600 PMid: 31322455

19. T. Ishida, F. Asano, K. Yamazaki, N. Shinagawa, S. Oizumi, H. Moriya, M. Munakata, M. Nishimura, "Virtual bronchoscopic navigation combined with endobronchial ultrasound to diagnose small peripheral pulmonary lesions: a randomised trial," Thorax, vol. 66, no. 12, pp. 1072-1077, Dec. 2011. https://doi.org/10.1136/thx.2010.14.54.90 PMid: 21749984

20. Sh. Li, W. Yan, M. Chen, Zh. Li, Y. Zhu, Q. Wu, "Virtual bronchoscopic navigation without fluoroscopy guidance for peripheral pulmonary lesions in inexperienced pulmonologist," Chin. J. Cancer Res., vol. 32, no. 4, pp. 530-539, Aug. 2020.

https://doi.org/10.21147/j.issn.1000-9604.2020.04.10 PMid: 32963465

21. T. Adachi, H. Machida, M. Nishikawa, T. Arai, T. Kariyasu, M. Koyanagi, K. Yokoyama, "Improved delineation of CT virtual bronchoscopy by ultrahigh resolution CT: comparison among different reconstruction parameters", Jpn J Radiol., vol. 38, no. 9, pp. 884-889, Apr. 2020. https://doi.org/10.1007/s11604-020-00972-y PMid: 32297061 